\title{
The Value of Studying Clinical and Serologic Phenotypes in North American Native Populations with Autoimmune Disease
}

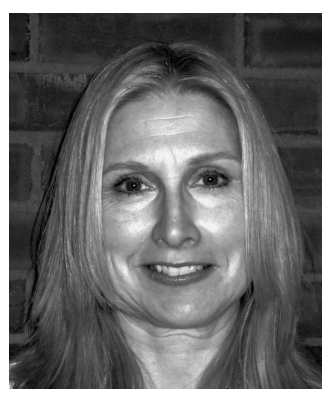

In the last 10-15 years there has been increasing awareness of a high rheumatic disease burden in North American Natives (NAN), resulting in a growing number of studies describing clinical and serological phenotypes in these populations. But what is the value of these largely descriptive studies?

In this issue of The Journal, Bacher and colleagues add to the body of literature on rheumatic disease in NAN populations, describing the manifestations and symptoms of scleroderma (systemic sclerosis; SSc) in a group of 71 Native Canadians ${ }^{1}$. This is the largest NAN cohort ever described with this relatively rare disease, and the authors suggest possible differences in the phenotype of SSc compared to white populations.

Variability in the phenotypic expression of many autoimmune diseases between different ethnicities has long been recognized; in NAN populations autoimmune disease is generally recognized to be severe ${ }^{2,3,4}$. At the very least, descriptions of disparate burdens of disease can help guide public health policy, and direct increased health resources to affected ethnic groups. Ethnicity, however, is a complex concept, which includes racial designations or genotypic groupings, but transcends them, representing instead the aggregate of cultural practices, lifestyle patterns, social influences, religious pursuits, and racial characteristics that shape the distinctive identity of a community ${ }^{5}$. Autoimmune diseases, such as SSc and systemic lupus erythematosus (SLE), are known to arise from a complex interaction between genetic, environmental, socioeconomic, cultural, and behavioral factors. The similarities between the factors shaping ethnicity and the factors shaping autoimmune disease are readily apparent; evidently the factors that differentiate and define ethnic groups may be some of the same ones that are important in understanding how complex autoimmune diseases develop and are expressed.

This leads to the obvious conclusion that studying ethnic cohorts can be of great value in determining the genetic and nongenetic factors that combine to cause and shape these diseases. This potential for studies of ethnic populations with autoimmune disease to improve our understanding of mechanisms of disease has been demonstrated by a number of investigators. One example, cited by Bacher, et al, is the studies of SSc in an Oklahoma Choctaw population. Investigators described a strikingly high prevalence rate of $>400 / 100,000$ in this population, associated with a specific HLA haplotype, HLA-DRB $1 *: 1602$ (DR2) ${ }^{6}$. Further work uncovered a founder effect as a contributor to differing prevalence rates between 2 Choctaw populations, and identified a 2-cM haplotype on chromosome 15q containing the fibrillin 1 gene associated with genetic susceptibility to $\mathrm{SSc}^{7}$.

The LUMINA cohort (LUpus in MInorities; NAture vs nurture) is another notable example. In 1994, investigators established a cohort of patients with SLE of Hispanic, African American, and white ancestry ${ }^{8}$. They were instrumental in describing the SLE phenotype in Hispanics, a group previously unrecognized to be at high risk of severe SLE. They later added a second group of Hispanics from Puerto Rico ${ }^{9}$ and demonstrated a different phenotype in these patients compared to the Texas Hispanic population, highlighting variable phenotypes, as well as socioeconomic, cultural, and genetic differences within this one ethnic group ${ }^{10}$. Among a very large body of work, these investigators also demonstrated that poverty had a greater influence on mortality than ethnicity ${ }^{11}$, and that genetic association studies conducted in one population group cannot be generalized to others ${ }^{9}$. This underscores the need for careful phenotypic descriptions to facilitate these association studies. LUMINA investigators have recognized the lack of homogeneity within ethnic designations, and are now choosing to pursue admixture proportions as a more refined measure of the genetic contribution to variability in disease ${ }^{12}$.

As in the Hispanic populations within the LUMINA

See SSc in Canada's native population, page 1121 
cohort, there may be as much or more variability within a single ethnic designation as between ethnic groups ${ }^{5}$. Canada, although occasionally struggling with the changing face of ethnic diversity, prides itself on its multicultural, multiethnic identity. At the same time, the astonishing diversity among NAN peoples is largely ignored. (A word about nomenclature: In the United States, indigenous peoples are referred to as North American Indians or Native Americans; in Canada, indigenous peoples are collectively referred to as Aboriginal people. Aboriginal is an umbrella term encompassing First Nations people, the Inuit, and the Métis: all descendants of the original inhabitants of North America.) Aboriginal people in Canada are certainly geographically diverse, residing in communities from the High Arctic to the plains, and from coast to coast. More than one-half of Canadian Aboriginals reside in urban areas, while others live on reserves. Some reserves are resource-rich, others not; some are very isolated, others are close to major urban centers; some are very small, others are large ${ }^{13}$. Linguistic diversity is also impressive: more than 60 different Aboriginal languages were reported in the most recent Canadian census ${ }^{14}$. There are more than 2000 reserves in Canada, affiliated with 617 First Nations ${ }^{15}$, and 566 Indian tribal entities are recognized in the United States $^{16}$. In addition, there are the Inuit residing in the Canadian far north and 2 distinct Métis groups ${ }^{13}$. These numerous Aboriginal groups have historically distinct cultures, and their current cultures are further influenced by the unique experiences these different groups have had in the last few centuries ${ }^{13}$. This diversity obliges us to be very cautious in presenting NAN as a homogenous group. From the standpoint of medical research and disease mechanisms, it is far from clear whether the commonalities outweigh the diversity.

The NAN cohort described in this issue is part of the Canadian Scleroderma Research Group registry, and included Inuit, First Nations, and Métis patients from 15 participating academic centers across Canada ${ }^{1}$, and is thus likely fairly representative of the diversity of Canadian Aboriginals. Is it appropriate to present them as a group with significant attributes in common? Perhaps as appropriate as it is to present whites as a single ethnic group, given the assortment of countries of origin, languages, religions, cultural heritage, and traditions that are represented in such a group. While the conclusions from this study must be interpreted with caution, to avoid premature labeling of a NAN SSc phenotype, it is an important beginning. It is notable that the landmark work cited above began with phenotypic descriptions, first arising when clinicians noted and documented disparities in their patients from different ethnic groups - disparities in prevalence, manifestations, or outcomes.

Ultimately, such descriptive studies are a stepping stone to a better understanding of the interaction of genetic, environmental, cultural, and social factors that lead to disease susceptibility and affect disease expression and outcomes. They are the first step, not only in identifying disparities in the burden of disease or access to care that can guide health policy and funding, but also in improving our understanding of causal mechanisms. Autoimmune diseases are increasingly being divided into many subphenotypes as new knowledge emerges. The eventual goal is more targeted therapy, and "personalized medicine" for all. To achieve this, we must be ever more cautious with classifications of ethnicity. Indeed, we must increasingly become "splitters" rather than "lumpers" to avoid masking the very factors we are trying to understand.

CHRISTINE PESCHKEN, MD, Department of Medicine,

University of Manitoba Arthritis Centre, RR149 Arthritis Centre,

800 Sherbrook Street,

Winnipeg, Manitoba R3A 1M4, Canada

Address correspondence to Dr. Peschken;

E-mail: cpeschken@exchange.hsc.mb.ca

\section{REFERENCES}

1. Bacher A, Mittoo S, Hudson M, Tatibouet S, Group CSR, Baron M Systemic sclerosis in Canada's North American Native population: assessment of clinical and serological manifestations. J Rheumatol 2013;40:1121-8.

2. Peschken CA, Esdaile JM. Rheumatic diseases in North America's indigenous peoples. Semin Arthritis Rheum 1999;28:368-91.

3. Ferucci ED, Templin DW, Lanier AP. Rheumatoid arthritis in American Indians and Alaska Natives: a review of the literature. Semin Arthritis Rheum 2005;34:662-7.

4. Reveille JD. Ethnicity and race and systemic sclerosis: how it affects susceptibility, severity, antibody genetics, and clinical manifestations. Curr Rheumatol Rep 2003;5:160-7.

5. O'Loughlin J. Understanding the role of ethnicity in chronic disease: a challenge for the new millennium. CMAJ 1999; 161:152-3.

6. Arnett FC, Howard RF, Tan F, Moulds JM, Bias WB, Durban E, et al. Increased prevalence of systemic sclerosis in a Native American tribe in Oklahoma. Association with an Amerindian HLA haplotype. Arthritis Rheum 1996;39:1362-70.

7. Tan FK, Stivers DN, Foster MW, Chakraborty R, Howard RF, Milewicz DM, et al. Association of microsatellite markers near the fibrillin 1 gene on human chromosome $15 q$ with scleroderma in a Native American population. Arthritis Rheum 1998;41:1729-37.

8. Reveille JD, Moulds JM, Ahn C, Friedman AW, Baethge B, Roseman J, et al. Systemic lupus erythematosus in three ethnic groups: I. The effects of HLA class II, C4, and CR1 alleles, socioeconomic factors, and ethnicity at disease onset. LUMINA Study Group. Lupus in minority populations, nature versus nurture. Arthritis Rheum 1998;41:1161-72.

9. Alarcon GS. Lessons from LUMINA: A multiethnic US cohort. Lupus 2008;17:971-6.

10. Vila LM, Alarcon GS, McGwin G Jr, Friedman AW, Baethge BA Bastian HM, et al. Early clinical manifestations, disease activity and damage of systemic lupus erythematosus among two distinct US Hispanic subpopulations. Rheumatology 2004;43:358-63.

11. Duran S, Apte M, Alarcon GS. Poverty, not ethnicity, accounts for the differential mortality rates among lupus patients of various ethnic groups. J Natl Med Assoc 2007;99:1196-8.

Personal non-commercial use only. The Journal of Rheumatology Copyright @ 2013. All rights reserved. 
12. Uribe AG, McGwin G Jr, Reveille JD, Alarcon GS. What have we learned from a 10-year experience with the LUMINA (Lupus in Minorities; Nature vs. nurture) cohort? Where are we heading? Autoimmun Rev 2004;3:321-9.

13. Voyageur C, Calliou B. Various shades of red: Diversity within Canada's Indigenous community. London J Can Stud 2000/2001;16:109-24

14. Statistics Canada. Aboriginal languages in Canada: Language, 2011 census of population. Catalogue no. 98-314-x2011003 2012. Ottawa: Statistics Canada. [Internet. Accessed May 3, 2013.] Available from: http://www12.statcan.gc.ca/census-recensement/ 2011/as-sa/98-314-x/98-314-x2011003_3-eng.pdf

15. Aboriginal Affairs and Northern Development Canada; Aboriginal peoples and communities: First Nations profiles. 2012. Ottawa:
Aboriginal Affairs and Northern Development Canada. [Internet. Accessed May 3, 2013.] Available from: http://pse5-esd5.ainc-inac.gc.ca/fnp/Main/index.aspx

16. US Federal Register. Indian entities recognized and eligible to receive services from the Bureau of Indian Affairs. Document No. 77 FR 47868. Washington, DC: US National Archives and Records Administration; 2012. [Internet. Accessed May 3, 2013.] Available from: https://www.federalregister.gov/articles/2012/08/10/ 2012-19588/indian-entities-recognized-and-eligible-to-receiveservices-from-the-bureau-of-indian-affairs

J Rheumatol 2013;40:1031-3; doi:10.3899/jrheum.130561 